Original Article

\title{
METFORMIN USAGE TO INDUCE OVULATION IN WOMEN WITH POLYCYSTIC OVARY SYNDROME: META-ANALYSIS
}

\section{LAIZA MARIA STEIMBACH ${ }^{a}$, ALINE DOS SANTOS LOUÇÃ $0^{b}$, CLAUDIA BATISTA CARRARO ${ }^{\mathrm{b}}$, FERNANDA STUMPF TONIN ${ }^{a}$, ROBERTO PONTAROLO ${ }^{a}$, ANDREIA CRISTINA CONEGERO SANCHES ${ }^{{ }^{*}}$}

aParaná Federal University, UFPR, Curitiba, Paraná, Brazil, bUniversity Estadual do Oeste do Paraná, UNIOESTE, Cascavel, Paraná, Brazil Email: andreiaconegero@gmail.com

Received: 15 Oct 2015 Revised and Accepted: 09 Sep 2016

\section{ABSTRACT}

Objective: To evaluate the use of MET in ovulation induction and pregnancy rates in a woman with polycystic ovary syndrome (PCOS).

Methods: A meta-analysis of randomised clinical trials (RCT) that presented ovulation and gestation rates in women with PCOS, after administering CC or M et al. one or combined was performed. The studies were selected according to the inclusion criteria in PCOS patients, resistant to CC or not.

Results: The meta-analysis demonstrated that MET and CC did not significantly increase the ovulation (Odds Ratio 1.72 [0.71, 4.12]) and gestation (OR $1.33[0.88,2.02]$ ) rates when compared to the usage of CC itself in women not resistant to CC. However, in women with CC-resistant PCOS, the group treated with CC and MET presented higher rates of ovulation (Odds Ratio $=14.57[4.96,42.81]$ ) and gestation (Odds Ratio $=11.86[2.45$, 57.36]) than patients treated only with CC.

Conclusion: The combination of MET and CC did not show advantages over the administration of CC alone in women not resistant to CC. However, MET may show satisfactory results in women resistant to CC.

Keywords: Ovulation induction, Pregnancy, Polycystic Ovary Syndrome, Metformin, Meta-analysis

(C) 2016 The Authors. Published by Innovare Academic Sciences Pvt Ltd. This is an open access article under the CC BY license (http://creativecommons. org/licenses/by/4. 0/) DOI: http://dx.doi.org/10.22159/ijpps.2016v8i11.9517

\section{INTRODUCTION}

Polycystic ovary syndrome (PCOS) is the most common hormonal and metabolic disorder among women in fertile age. It is clinically and/or biochemically characterised by hyperandrogenism, oligo or amenorrhea and ovaries with polycystic morphology [1]. Therefore, anovulation and consequently infertility are some of the symptoms of PCOS patient's [2].

In these cases, to treat anovulation, $\mathrm{CC}$ is the first-line therapy used $[3,4]$. Its usage results in ovulation in about $75-80 \%$ of patients [5], in which only $33-45 \%$ of them get pregnant [6]. For patients that do not respond to the treatment with CC, other options are possible, like therapies with gonadotropin, bromocriptine, tamoxifen, dexamethasone, and laparoscopic ovarian drilling [7]. However, it is also recommended the addition of MET to the therapy with CC, for patients who had not initially responded to the treatment with CC alone [8].

The treatment of choice for infertility in PCOS patients would be the combination of Metal ong with CC [9]. Nonetheless, in randomised clinical trials [10], it was also settled that the MET combined with CC is an effective treatment, both in ovulation induction and in reaching gestation in women affected by PCOS.

The usage of MET has been persistently cited as an important treatment for infertility caused by PCOS [3, 4, 11-13].

MET is a biguanide used mainly in noninsulin-dependent diabetes mellitus patients. Its usage in PCOS is owing to the decrease of high concentrations of insulin, which consequently reduces androgens production, though regularising the production of estrogens and restoring the ovarian hormonal balance [14].

Therefore, the aim of this study was to evaluate the relation of MET to the induction of ovulation in PCOS patients.

\section{MATERIALS AND METHODS}

For the systematic review, searches on the following electronic databases were carried: Cochrane, Lilacs, Scielo, Scopus, Science Direct, and PubMed. A time limit for the search was not established, and the used strategies were Metformin and fertility and "randomized clinical trial"; Metformin and "ovulation induction" and "randomized clinical trial" and Metformin and "polycystic ovary syndrome" and "randomized clinical trial". Publications available in English, Spanish and Portuguese, were evaluated. All studies were randomized clinical trials that compared the use of metformin versus clomiphene citrate or metformin and clomiphene citrate versus isolated clomiphene citrate. The evaluated outcomes were ovulation rate, gestation rate, as well as patients with definitive diagnostic of PCOS, with no other comorbidity that could compromise their fertility.

The studies should also present a clear definition of resistance, or not, to the usage of isolated $\mathrm{CC}$, since the comparison between the uses of this drug in resistant and non-resistant patients is part of the current meta-analysis approach. Following PRISMA (Preferred Reporting Items for Systematic Reviews and Meta-Analyses) recommendations titles and abstracts of records retrieved were initially screened and the full text of those considered relevant was then analysed. The literature selection process was conducted by two independent reviewers (Steimbach L. M. e Loução A. S.), with a third reviewer in the case of discrepancies (Sanches A. C. C.).

No studies were not excluded by quality methodological reasons.

The meta-analysis was done according to Cochrane's recommendations and with the help of Review Manager 5.2 software. Odds Ratio (OD) was calculated to summarise all outcomes, with $95 \%$ confidence intervals (CI). The statistic was random effects with Inverse of the Variance (IV) and MantelHaenszel (M-H).

\section{RESULTS AND DISCUSSION}

2586 articles were found on the systematic research (fig. 1), from which 1640 were duplicates. Part of these was excluded by the title and abstracts reading and part by the full-article evaluation. A total of 11 RCT met the inclusion criteria. 


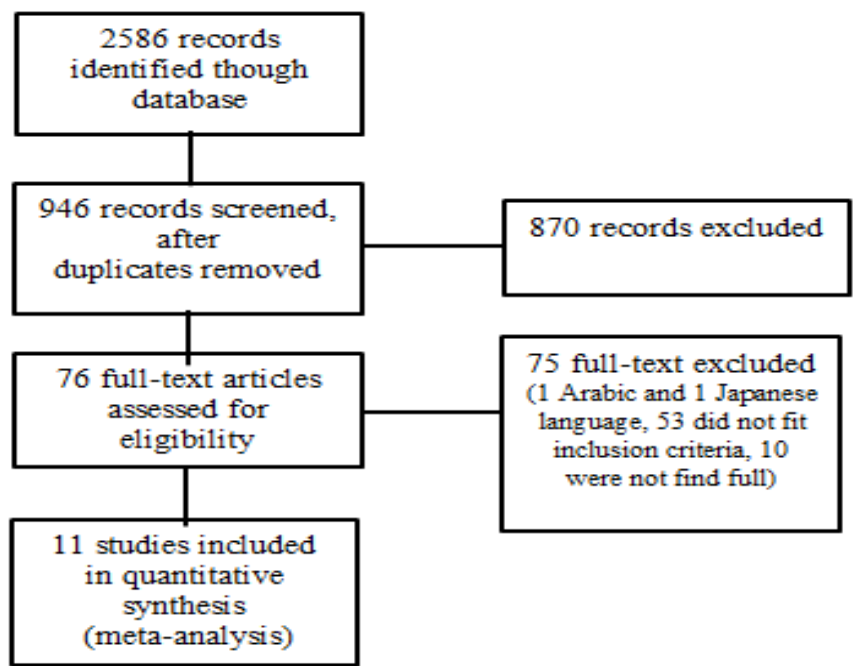

Fig. 1: Flowchart of included studies

The participants-a total of 1451-of the included studies presented an average age of 27.6 y old (25.0 \pm 29.5$)$ and body mass index of 32.5 $\left(25.0 \pm 38.0 \mathrm{Kg} / \mathrm{m}^{2}\right)$.
There was no statistically significant difference between combined MET + CC versus CC, in the studies of induction of ovulation and gestation in women with no resistance to CC (fig 2 and 3).

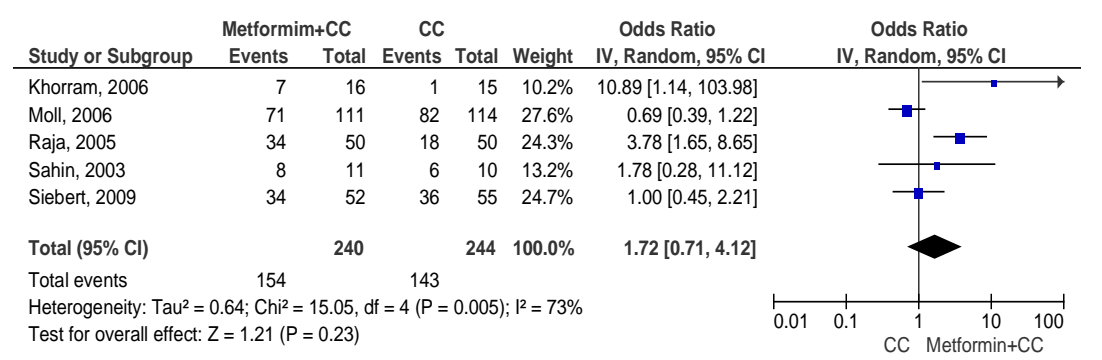

Fig. 2: Forest plot for ovulation rates in nonresistant patients to clomiphene citrate. Statistical method: odds ratio (I-V Random, $95 \%$ I). Test for overall effect done using review manager software

On fig 2 , the global effect-OR $1.72[0.71,4.12]$-shows that there is no favouring of any kind of treatment for the outcome ovulation rate in nonresistant women to CC.

The heterogeneity of the meta-analysis was high $(73 \%)$, which means that there is a great methodological variability among the studies. The five studies used in this meta-analysis have a duration period and a number of patients very variable among one another, which is a reason that contributes to the found heterogeneity. The duration of the clinical trials published by Khorram et al. 2006 and Raja et al. 2005 were different and lasted $1 \mathrm{mo}$ and $6 \mathrm{mo}$, respectively. The others presented time horizons between two and four years. The hypothetical removal of these two studies reduced the heterogeneity to $0 \%$, without altering the result, though.

\begin{tabular}{|c|c|c|c|c|c|c|c|c|c|}
\hline \multirow{2}{*}{$\frac{\text { Study or Subgroup }}{2.1 .1 \text { Metformin }+C C}$} & \multicolumn{2}{|c|}{ Metformin+CC } & \multicolumn{2}{|l|}{ cc } & \multicolumn{3}{|c|}{ Odds Ratio } & \multicolumn{2}{|c|}{$\begin{array}{c}\text { Odds Ratio } \\
\mathrm{M}-\mathrm{H}, \text { Random, } 95 \% \mathrm{Cl}\end{array}$} \\
\hline & & & & & & & & & \\
\hline Johnson, 2010 & 19 & 35 & 14 & 36 & $12.0 \%$ & $1.87[0.73,4.80]$ & & & $\because$ \\
\hline Khorram, 2006 & 5 & 16 & 0 & 15 & $2.8 \%$ & $14.83[0.74,295.97]$ & & & \\
\hline Legro, 2007 & 80 & 209 & 62 & 209 & $17.0 \%$ & $1.47[0.98,2.21]$ & & & $=$ \\
\hline Moll, 2006 & 44 & 111 & 52 & 114 & $16.0 \%$ & $0.78[0.46,1.33]$ & & & \\
\hline Sahin, 2003 & 5 & 11 & 3 & 10 & $6.1 \%$ & $1.94[0.32,11.76]$ & & & \\
\hline $\begin{array}{l}\text { Zain, } 2009 \\
\text { Subtotal }(95 \% \mathrm{Cl})\end{array}$ & 8 & $\begin{array}{r}38 \\
420\end{array}$ & 6 & $\begin{array}{r}39 \\
423\end{array}$ & $\begin{array}{l}10.1 \% \\
64.0 \%\end{array}$ & $\begin{array}{r}1.47[0.46,4.72] \\
1.33[0.88,2.02]\end{array}$ & & & $t$ \\
\hline $\begin{array}{l}\text { Total events } \\
\text { Heterogeneity: } \text { Tau }^{2}= \\
\text { Test for overall effect: }\end{array}$ & $\begin{array}{c}161 \\
.08 ; \mathrm{Ch}^{2}= \\
=1.35(\mathrm{P}\end{array}$ & $\begin{array}{l}7.22, \mathrm{df} \\
=0.18)\end{array}$ & $\begin{aligned} & 137 \\
= & 5(P=C\end{aligned}$ & $0.20) ; 1$ & ${ }^{2}=31 \%$ & & & & \\
\hline 2.1.2 Metformin & & & & & & & & & \\
\hline Johnson, 2010 & 14 & 35 & 14 & 36 & $11.9 \%$ & $1.05[0.40,2.71]$ & & & - \\
\hline Legro, 2007 & 25 & 208 & 62 & 209 & $16.1 \%$ & $0.32[0.19,0.54]$ & & $\rightarrow$ & \\
\hline $\begin{array}{l}\text { Zain, } 2009 \\
\text { Subtotal }(95 \% \mathrm{Cl})\end{array}$ & 3 & $\begin{array}{r}38 \\
281\end{array}$ & 6 & $\begin{array}{r}39 \\
284\end{array}$ & $\begin{array}{r}7.9 \% \\
36.0 \%\end{array}$ & $\begin{array}{l}0.47[0.11,2.04] \\
0.51[0.23,1.13]\end{array}$ & & & \\
\hline $\begin{array}{l}\text { Total events } \\
\text { Heterogeneity: Tau² } \\
\text { Test for overall effect: }\end{array}$ & $\begin{array}{r}42 \\
.27 ; \mathrm{Chi}^{2}= \\
=1.66(\mathrm{P}\end{array}$ & $\begin{array}{l}4.55, \mathrm{df} \\
=0.10)\end{array}$ & $\begin{aligned} & 82 \\
2 & (P=C\end{aligned}$ & $0.10) ; \mathrm{l}$ & ${ }^{2}=56 \%$ & & & & \\
\hline Total $(95 \% \mathrm{Cl})$ & & 701 & & 707 & $100.0 \%$ & $1.02[0.59,1.76]$ & & & \\
\hline Total events & 203 & & 219 & & & & & & \\
\hline $\begin{array}{l}\text { Heterogeneity: } \mathrm{Tau}^{2}= \\
\text { Test for overall effect: }\end{array}$ & $\begin{array}{l}.41 ; \mathrm{Chi}^{2}= \\
=0.07(\mathrm{P} \\
\text { ences }\end{array}$ & $\begin{array}{l}28.99, \mathrm{c} \\
=0.94)\end{array}$ & $f=8(P$ & 0.000 & 3); $1^{2}=7$ & & 0.02 & $0.1 \mathrm{cc}$ & $\begin{array}{l}1 \\
1 \\
\end{array}$ \\
\hline
\end{tabular}

Fig. 3: Forest plot for gestation rates in nonresistant patients to clomiphene citrate. Statistical method: odds ratio (M-H Random, 95\% CI). Test for overall effect done using review manager software 
The meta-analysis for the outcome of gestation in nonresistant patients to CC showed an overall effect of OR $1.33[0.88,2.02]$ and a moderate heterogeneity (31\%). This result is completely modified by the hypothetical removal of Moll et al. (2006) study, from which a $0 \%$ heterogeneity is obtained, as well as a result that favours the combined treatment of MET+CC (Odds Ratio $=1.58[1.12,2.24])$. It occurs because Moll et al. (2006) is the only study that presents the greater percentage of events favouring the treatment with CC only, while the combined treatment is favoured within all the other studies. In this study, each woman was evaluated by several cycles in which they had the clomiphene dosage increased from 50 to $150 \mathrm{mg}$ a day. So the reason of the cumulative ovulation was evaluated, not the number of cycles. This unique methodological difference justifies the heterogeneity found because all other included articles evaluate each patient for six cycles. The evaluation of gestation rates compared between MET versus CC shows no differences that could favour any of the treatments.

Though, the hypothetical removal of a study made by Johnson et al. (2010) reduced the heterogeneity from $56 \%$ to $0 \%$ and favoured the treatment with CC only (Odds Ratio: 0.34 [0.21, 0.55]). This can be justified because the results in the study favoured the treatment with MET only. Studies published by Legro, 2007 and Zain, 2009 have a smaller number of MET+CC patients compared with the patients from the CC group, while Johnson et al. has the same number of patients in both groups.

Several authors have not found statistically significant evidence that could favour the outcome of gestation in neither of the treatments (MET or CC) [15-17].

The meta-analysis from studies with patients resistant to CC presented a statistically significant result, favouring the usage of $\mathrm{MET}+\mathrm{CC}$, (fig 4 and 5). In both meta-analyses, the heterogeneity was $0 \%$, which shows there are no methodological or statistical differences among themselves and that the result is robust. The resistance to $\mathrm{CC}$ is defined in these studies as the non-ovarian response to the usage of $150 \mathrm{mg}$ of this drug for 5 straight days, during 3 consecutive menstrual cycles.

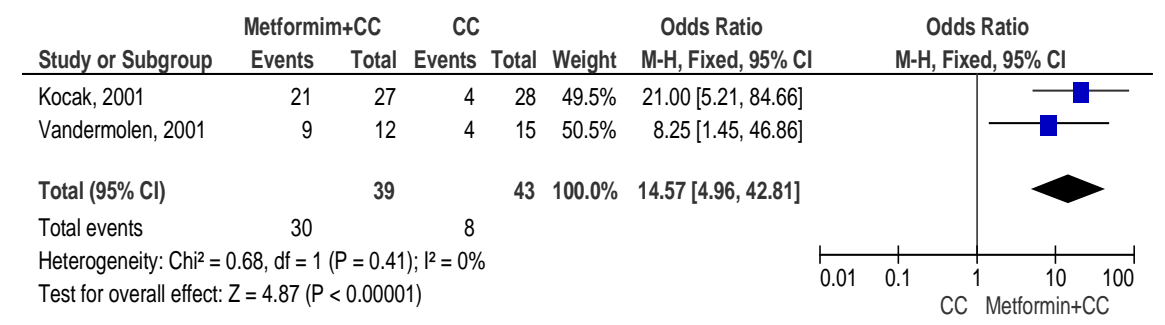

Fig. 4: Forest plot for ovulation rates in resistant patients with clomiphene citrate: odds ratio (M-H random, 95\% $\mathrm{CI}$ ). Test for overall effect done using review manager software

Similar results were observed in another meta-analysis in which OR $=1.27[1.03,1.56][18]$. However, this study does not report the existence or not of resistance to $\mathrm{CC}$, which methodologically differentiates it from the current study.

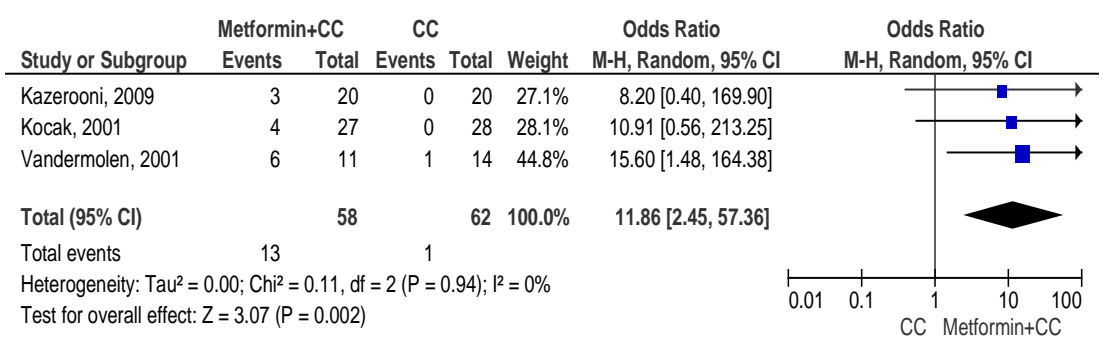

Fig. 5: Forest plot for gestation rates in resistant patients to Clomiphene Citrate. Statistical method: odds ratio (M-H random, $95 \% \mathrm{CI}$ ). Test for overall effect done using review manager software

Results obtained in other studies agree with the ones described above and also demonstrates that patients resistant to CC present better results when MET is combined with CC $[19,20]$. There is an evident increase on ovulation rates $(\mathrm{OR}=1.6,95 \%$ CI 1.2-2.1, $\mathrm{p}=$ 0.0009 and $(\mathrm{OR}=7.31,95 \% \mathrm{CI}: 2.57-20.76, \mathrm{P}<0.0 \mathrm{dx} 5)$ and gestation rates $(\mathrm{OR}=1.3,95 \% \mathrm{CI} 1.0-1.6, \mathrm{p}=0.05)$ (OR $=7.93,95 \% \mathrm{CI}: 2.45$ $25.63, \mathrm{P}<0.05$ ) that can benefit patients.

\section{CONCLUSION}

MET can be administered concomitantly to the usage of CC, so satisfactory results are obtained in patients resistant to CC, by increasing the ovulation and gestation rates, when compared to the usage of $\mathrm{CC}$ only. Yet, in patients that do not present resistance to $\mathrm{CC}$, the usage of MET as an adjuvant on the treatment does not present statistically significant results that would favour its usage.

\section{CONFLICTS OF INTERESTS}

The authors declare they have no conflicts of interest.

\section{REFERENCES}

1. Gődény $\mathrm{S}$, Csenteri 0 . Importance of the interdisciplinary, evidence-based diagnosis of polycystic ovary syndrome. Orv Hetil 2014;155:1175-88.

2. Díaz JFJ, González CO. Síndrome de ovario poliquístico. Rev Mexicana Med Reproducción 2011;4:51-62.

3. AL-Inany H, JOHNSON N. Drugs for anovulatory infertility in polycystic ovary syndrome: reserve metformin for second line treatment for women with clomifene resistance. Br Med J 2006;332:1461-2.

4. SEMPR: Serviço de endocrinologia e metabologia-hospital das clínicas da universidade federal do paraná. Disponível em: Available from http://www.sempr.org.br/protocolos/ protocolo06.asp. [Last accessed on 17 Mar 2014].

5. Amin M, Abdel-Kareem O, Takekida S, Moriyama T, Abdel-Aal G, MARUO T. Update management of non-responder to clomiphene citrate in polycystic ovary syndrome. Kobe J Med Sci 2003;49:59-73. 
6. Costello MF, Eden JA. A systematic review of the reproductive system effects of metformin in patients with polycystic ovary syndrome. Fertil Steril 2003;79:1-13.

7. Kazerooni T, Ghaffarpasand F, Kazerooni Y, Setoodeh S. Shortterm metformin treatment for clomiphene citrate-resistant women with polycystic ovary syndrome. Int J Gynaecol Obstet 2009;107:50-3.

8. American College of Obstetricians and gynaecologists (ACOG). management of infertility caused by ovulatory dysfunction. Washington, DC. Practice bulletin; 2002. p. 34.

9. Panidis D, Tziomalos K, Papadakis E, Katsikis I. Infertility treatment in polycystic ovary syndrome: lifestyle interventions, medications and surgery. Front Horm Res 2013;40:128-41.

10. Abu Hashim H, EL Lakany N, Sherief L. Combined metformin and clomiphene citrate versus laparoscopic ovarian diathermy for ovulation induction in clomipheneresistant women with polycystic ovary syndrome: a randomised controlled trial. J Obstet Gynaecol Res 2011;37:169-77.

11. Begum MR, Akhter S, Ehsan M, Begum MS, Khan F. Pretreatment and co-administration of the oral anti-diabetic agent with clomiphene citrate or $\mathrm{rFSH}$ for ovulation induction in clomiphene-citrate-resistant polycystic ovary syndrome. J Obstet Gynaecol Res 2013;39:966-73.

12. Moll E, bossuyt PMM, Korevaar JC, Lambalk CB, Van Der Veen F. Effect of clomifene citrate plus metformin and clomifene citrate plus placebo on induction of ovulation in women with newly diagnosed polycystic ovary syndrome: randomised doubleblind clinical trial. Br Med J 2006;332:1485.

13. Velazquez EM, Mendoza S, Hamer T, Sosa F, Glueck CJ. Metformin therapy in polycystic ovary syndrome reduces hyperinsulinemia, insulin resistance, hyperandrogenemia, and systolic blood pressure while facilitating normal menses and pregnancy. Metabolism 1994;43:647-54.
14. Santana LF, Ferriani RA, Sá MFS, Reis RM. Tratamento da infer tilidate em mulheres com síndrome dos ovários policísticos. Rev Bras Ginecol Obstet 2008;30:201-9.

15. Johnson N. Metformin is a reasonable first-line treatment option for non-obese women with infertility related to anovulatory polycystic ovary syndrome--a meta-analysis of randomised trials. Aust N Z J Obstet Gynaecol 2011;51:125-9.

16. Misso ML, Costello MF, Garrubba M, Wong J, Rombauts L, Melder $\mathrm{AM}$, et al. Metformin versus clomiphene citrate for infertility in non-obese women with polycystic ovary syndrome: a systematic review and meta-analysis. Hum Reprod Update 2013;19:2-11.

17. Xiao J, Chen S, Zhang C, Chang S. The effectiveness of metformin ovulation induction treatment in patients with PCOS: a systematic review and meta-analysis. Gynecol Endocrinol 2012;28:956-60.

18. Sun X, Zhang D, Zhang W. Effect of metformin on ovulation and reproductive outcomes in women with polycystic ovary syndrome: a meta-analysis of randomised controlled trials. Arch Gynecol Obstet 2013;288:423-30.

19. Siebert TI, Viola MI, Steyn DW, Kruger TF Is metformin indicated as primary ovulation induction agent in women with PCOS? A systematic review and meta-analysis. Gynecol Obstet Invest 2012;73:304-13.

20. Wang LL, Ren W, Cheng QF, Fan XD. Therapeutic effect of metformin for clomiphene-resistant infertility patients with polycystic ovary syndrome: a systematic analysis. Zhonghua Fuchanke Zazhi 2012;47:659-63.

\section{How to cite this article}

- Laiza Maria Steimbach, Aline Dos Santos Loução, Claudia Batista Carraro, Fernanda Stumpf Tonin, Roberto Pontarolo, Andreia Cristina Conegero Sanches. Metformin usage to induce ovulation in women with polycystic ovary syndrome: a metaanalysis. Int J Pharm Pharm Sci 2016;8(11):86-89. 